
wildlife crime: recovery of human DNA deposited outside. Forensic Science International: Genetics , 35, 65-69. https://doi.org/10.1016/j.fsigen.2018.04.002

\title{
1 Profiling in wildlife crime: recovery of human DNA deposited outside
}

K. Mcleish, S. Ferguson, C Gannicliffe, S. Campbell, P.I.T. Thomson, L.M.I.

\section{Webster}

\section{Abstract}

Incidents of bird of prey persecution receive a lot of media coverage in the UK, with investigations rarely recovering sufficient evidence to proceed to prosecution. One of the main challenges is to identify a suspect, as these offences are carried out in remote locations without witnesses, and crime scenes may not be found for days. However, traps, poisoned baits and bird of prey carcasses can be recovered from these crime scenes. This study aimed to determine whether reportable human DNA profiles could be recovered from any of these substrates after periods of time outside.

Experiments depositing human touch DNA on duplicate substrates (traps, rabbit baits and corvid carcasses) set for 0,1, 2, 4, 7 and 10 days outside were carried out, with DNA recovery and profiling following standard operating procedures for Scottish Police Authority Forensic Services. Weather conditions varied among experiments, including some heavy rainfall. Results demonstrated that it was possible to obtain reportable DNA profiles from all substrates after at least 1 day outside. Most promisingly, the traps showed no drop-off in DNA persistence over the experiments as complete DNA profiles were obtained after the full 10 days outside. A further experiment using 4 bird of prey carcasses confirmed that it is possible to obtain reportable human DNA profiles from them after 1 day outside $(n=2$ reportable profiles). These results show that touch DNA can persist in an outdoor environment, and provide a tantalising avenue for inquiry in bird of prey persecution investigations.

\section{Introduction}

Despite birds of prey having legal protection in Scotland since the 1950s, persecution is still a prominent issue. The principle reasons for this are conflicts between some gamebird shooting interests and a wide range of raptor species [Ref A, Ref B], conflict between some elements of the livestock industry, in particular low- 
This is a peer-reviewed, accepted author manuscript of the following research article: Mcleish, K., Ferguson, S., Gannicliffe, C., Campbell, S., Thomson, P. I. T., \& Webster, L. M. I. (2018). Profiling in wildlife crime: recovery of human DNA deposited outside. Forensic Science International: Genetics , 35, 65-69. https://doi.org/10.1016/j.fsigen.2018.04.002

intensity sheep-farming, and eagles, and the targeting of hawks and falcons by some individuals or groups who seek to protect their racing pigeons from predation [1-3 Ref C]. The persecution of raptors can occur at any time of year either in response to particular seasonal issues such as lambing or the release of pheasant poults, or it may be undertaken opportunistically at any time..

There were 280 recorded bird-related offences in Scotland from 2010-2015 with just $16 \%$ of these cases resulting in convictions [4]. Many of these crimes take place in remote or hard to access locations making it difficult to gather sufficient evidence to identify and prosecute the perpetrators, forensic evidence in particular can often be lacking. Persecution of birds of prey can have a substantial impact on populations at the local, regional and even national level [4-5], as some of the species involved are rare and endangered. This can lead to substantial pressure to increase convictions and reduce offending [3-4]. The most common methods for killing birds of prey are shooting, poisoning, trapping and nest destruction [4]. In many of these instances the offender will have to either handle a trap, a bait or the bird itself, potentially depositing touch DNA in the process. The recovery of touch DNA from many substrates during forensic investigations is routine and widely accepted around the world [6-9]. However, it is rarely applied to evidence recovered outside, and there are no reports of these techniques being used successfully to recover human touch DNA from bird of prey crime scenes.

As with other crime types, human DNA could be a key tool to link individuals to scenes, items to scenes and items together [10-13]. The discovery of human DNA on a bird of prey carcass would be particularly significant because there are few explanations for its presence. Two published studies are available investigating the recovery of human DNA from animal carcasses [14, 15]. Here, human touch DNA was recovered from the legs of deer immediately following slaughter. Samples from 5 out of 10 deer produced reportable results. However, this study did not investigate whether recovery of DNA would be affected by the length of time a substrate spent outside. Due to the remote location of these crimes, scenes may not be discovered for many days after the crime took place, if indeed they are found at all. There is therefore a need to investigate the persistence of human DNA on animal carcasses 
This is a peer-reviewed, accepted author manuscript of the following research article: Mcleish, K., Ferguson, S., Gannicliffe, C., Campbell, S., Thomson, P. I. T., \& Webster, L. M. I. (2018). Profiling in wildlife crime: recovery of human DNA deposited outside. Forensic Science International: Genetics , 35, 65-69. https://doi.org/10.1016/j.fsigen.2018.04.002

and crime items that are recovered outside, because weather conditions can vary considerably in Scotland and exposure to inclement conditions might be encountered in casework at any time of year.

While research has been carried out on DNA persistence indoors [16], significantly less research is available concerning the persistence of DNA on objects and surfaces in outdoor conditions. A study by Raymond et al. [17] found that the concentration of DNA solutions left exposed halved after 2 weeks, but there was no clear trend in DNA loss over the time period, suggesting that multiple factors were involved.

This study aims to determine whether existing human DNA profiling techniques can be utilised to recover offender touch DNA from bird of prey carcasses, poisoned bait carcasses and traps that have been left outside for up to 10 days. This key identification tool would offer a significant advancement in the investigation of wildlife crimes and indeed any crime where DNA evidence has been exposed to the elements.

\section{Materials and Methods}

\subsection{Substrates}

Springer Mark 6 traps were used for the trap experiments $(n=12)$. All the traps showed a similar degree of mild corrosion. The rabbits, which are often used as poisoned baits, and corvids, as a proxy for a bird of prey carcass, were legally killed as part of normal land management activity. Four bird of prey carcasses (buzzard, sparrowhawk, kestrel and tawny owl) were donated to the project having died of natural causes.

\subsection{DNA Transfer}

The individual shedder status of 3 participants was assessed using the methods described in Lowe et al. [18] (minitapes and 5 minute holding time) to ensure that a poor DNA shedder was not selected for the experiments (S1). An initial proof of concept experiment demonstrated that full STR profiles could be obtained from all substrates immediately after handling (S2). Prior to handling the items, the 
participant refrained from hand washing activities for 1 hour, but continued daily tasks. A 10-minute interval was taken between handling each item. For the traps the participant used both hands to set the trap and hold it until 1 minute had elapsed. For the rabbit carcasses the participant was asked to carry the rabbit by holding the back legs in one hand for a period of 1 minute. The corvid and bird of prey carcasses were held in one hand for a period of 1 minute. The palm was placed on the birds' back, with fingers wrapped around the neck and upper body area, enclosing the folded wings.

\subsection{Experimental Set-up}

DNA was deposited by a single participant onto the different substrates and these were left either outside or inside for 0 to 10 days, as detailed in Table 1. Duplicate substrates for each time period within an experiment were run wherever possible. Experimental substrates left indoors were placed on a sterile plastic tray at room temperature, whereas those left outside were placed on the ground in a flat grassy compound. A wood and chicken wire cage structure was placed over the experimental substrates left outside to prevent access by wildlife without sheltering the items from rainfall or sunlight.

\begin{tabular}{|c|c|c|c|c|c|}
\hline $\begin{array}{c}\text { Location of substrate } \\
\text { exposure period }\end{array}$ & \multicolumn{5}{|c|}{ Experiment } \\
\cline { 2 - 6 } & $\begin{array}{c}\text { Trap } \\
\text { Expt1 }\end{array}$ & $\begin{array}{c}\text { Trap } \\
\text { Expt2 }\end{array}$ & $\begin{array}{c}\text { Rabbit } \\
\text { Expt3 }\end{array}$ & $\begin{array}{c}\text { Corvid } \\
\text { Expt4 }\end{array}$ & $\begin{array}{c}\text { Corvid } \\
\text { Expt5 }\end{array}$ \\
\hline Inside / 0 days (control) & 2 & 2 & 2 & 2 & 0 \\
\hline Outside / 1 day & 2 & 2 & 2 & 2 & 2 \\
\hline Outside / 2 days & 2 & 0 & 0 & 2 & 2 \\
\hline Outside / 4 days & 2 & 2 & 2 & 2 & 2 \\
\hline Outside / 7 days & 2 & 2 & 2 & 2 & 2 \\
\hline Outside / 10 days & 2 & 2 & 2 & 2 & 0 \\
\hline Inside / 10 days (control) & 2 & 0 & 1 & 2 & 0 \\
\hline
\end{tabular}


This is a peer-reviewed, accepted author manuscript of the following research article: Mcleish, K., Ferguson, S., Gannicliffe, C., Campbell, S., Thomson, P. I. T., \& Webster, L. M. I. (2018). Profiling in wildlife crime: recovery of human DNA deposited outside. Forensic Science International: Genetics , 35, 65-69. https://doi.org/10.1016/j.fsigen.2018.04.002

Table 1: Number of substrates used, and different treatments involved in experiments 1 to 5 .

Due to limited availability of traps and carcasses, not all time periods were completed for each experiment, and the two trap experiments and corvid experiments are not exact replicates (Table 1). A final small experiment, Experiment 6 , was carried out using the 4 bird of prey carcasses which were handled as described for the corvids and left for 1 day outdoors.

Experiments were not run concurrently, but began on different days over a one month period (June/July 2017). Data on rainfall during the experiments was obtained from the Met Office Monthly Climate Report for Edinburgh Gogarbank (S3).

\subsection{DNA Recovery}

Experimental substrates were collected and left indoors on a sterile plastic tray to dry (30 mins for traps and $1 \mathrm{hr}$ for carcasses). These durations were chosen as it is unlikely that DNA recovery would be attempted at the scene in wet conditions. A proof of concept study suggested the minitaping method was better for DNA recovery from these substrates than the double-swab method (S2). All experiments used minitapes for DNA recovery, as per the standard operating procedure used by the Scottish Police Authority (SPA) Forensic Services. The minitape (Scenesafe, WA Products) was applied to the sample area with pressure multiple times until adhesiveness was lost. The tapes were transported to the SPA laboratory and the adhesive section of the tape was removed and placed into an Autolys tube (Hamilton Robotics) before submission for DNA profiling.

\subsection{DNA Profiling}

Samples were processed on the AutoLys STAR and ID STARlet automated platforms (Hamilton Robotics). DNA was extracted using the PrepFiler DNA extraction kit, and amplified using the GlobalFiler PCR kit on the Veriti thermal cycler (AppliedBiosystems ${ }^{\mathrm{TM}}$ ). PCR product was run on the 3500xL Genetic Analyzer and 
This is a peer-reviewed, accepted author manuscript of the following research article: Mcleish, K., Ferguson, S., Gannicliffe, C., Campbell, S., Thomson, P. I. T., \& Webster, L. M. I. (2018). Profiling in wildlife crime: recovery of human DNA deposited outside. Forensic Science International: Genetics , 35, 65-69. https://doi.org/10.1016/j.fsigen.2018.04.002

139 the profiles analysed using GeneMapper ID-X software, version 1.5 140 (AppliedBiosystems ${ }^{\mathrm{TM}}$ ).

141

\subsection{Data Interpretation}

The resulting GlobalFiler STR profiles were initially examined on GeneMapper ID-X for any profile artefacts. The presence or absence of DNA from a contributor other than the donor was assessed and the number and type of alleles at each locus was noted. The following criteria, derived by SPA Forensic Services during validation, were used for all loci excluding Yindel and DYS391 for reporting of profiles:

- Two peaks at a locus = heterozygous.

- 1 Peak $>400$ rfu peak height $=$ homozygous.

- 1 Peak <400rfu peak height = potentially heterozygous with allele drop out.

- 0 Peaks $=$ No result.

DNA profiles were then compared to the participant's reference profile and the number of alleles present out of 46 was counted and converted to a percentage. Profiles in this study that were reviewed and considered to be reportable were more than $50 \%$ complete, i.e. at least 23 of a possible 46 alleles present.

To statistically assess the effect of experimental treatment (i.e. time outside) on the percentage of complete STR profile produced, analysis of variance (ANOVA) was performed for each experiment, carrying out data transformation where necessary. 
This is a peer-reviewed, accepted author manuscript of the following research article: Mcleish, K., Ferguson, S., Gannicliffe, C., Campbell, S., Thomson, P. I. T., \& Webster, L. M. I. (2018). Profiling in wildlife crime: recovery of human DNA deposited outside. Forensic Science International: Genetics , 35, 65-69. https://doi.org/10.1016/j.fsigen.2018.04.002

159

160

161

\section{Results and Discussion}

\subsection{Trap experiments}

Good quality DNA profiles were recovered from almost all of the traps in experiment 1 (Figure 1). Those from all but 2 traps, one of which had been left indoors for 10 days, were at least $50 \%$ complete. However, there was great variation between the duplicates indicating that time outside was not the only major factor influencing the recovery of DNA (Figure 1). There was less variance in the percentage of DNA profile obtained in experiment 2 with most duplicates collected on the same day producing similar qualities of profiles, and all samples producing reportable profiles of at least $50 \%$ complete (Figure 1). Treatment did not affect DNA profile recovery over the course of these experiments (Expt 1:F(6,7)=464, $p=0.49$; Expt2: $F(4,5)=274.9, p=0.572)$.

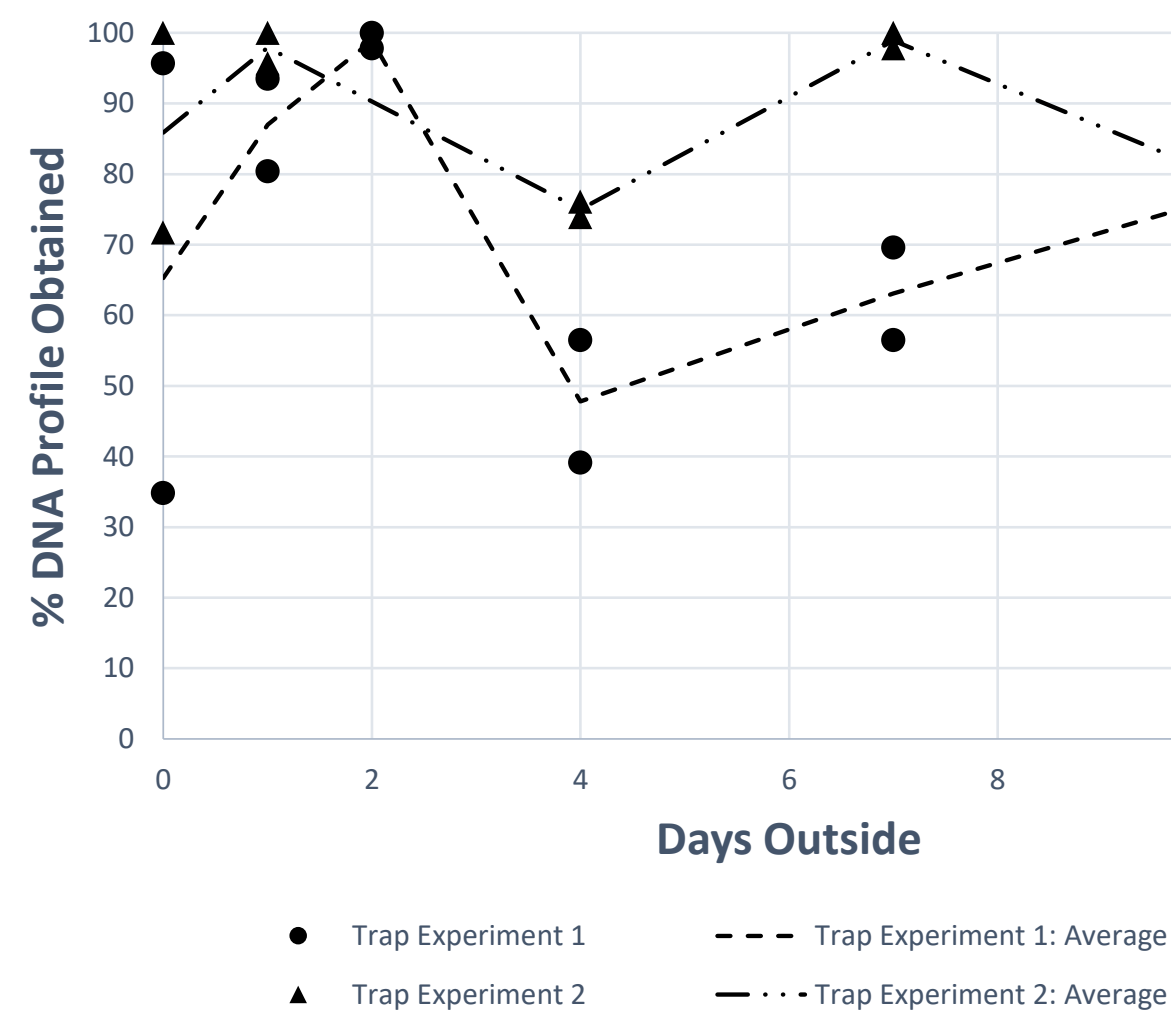

Figure 1: Percentage of DNA profile obtained (\%) from samples collected from traps left outside in experiment 1 and 2. The two points at each time period represent two separate trap samples on the same day at the same time. The line links the 
This is a peer-reviewed, accepted author manuscript of the following research article: Mcleish, K., Ferguson, S., Gannicliffe, C., Campbell, S., Thomson, P. I. T., \& Webster, L. M. I. (2018). Profiling in wildlife crime: recovery of human DNA deposited outside. Forensic Science International: Genetics , 35, 65-69. https://doi.org/10.1016/j.fsigen.2018.04.002

average percentage DNA profiles from one time period to the next to assess for a trend in the results.

Importantly, most of the profiles obtained from both experiments were of sufficient quality to be reported in a police investigation. Although all traps picked for this experiment exhibited a similar degree of corrosion, the microscopic surface texture of each trap could be completely different. This may have caused the differences observed between the duplicates and the variance in quality of profiles over time. Indeed, the two traps left indoors for 10 days for experiment 1 gave very different results (10.9\% and $87 \%$ complete STR profiles respectively). New corrosion-free traps could have been used but they would not represent the common condition of traps used in real crimes. Most of the contact points sampled existed on the underside of the trap as these are the areas touched during trap set up. These areas are protected from direct rainfall, which may account for the persistence of DNA on the traps after heavy rain.

Although efforts were made to standardise both trap experiments, the weather conditions were substantially different (S3). By day ten the experiment 1 traps had been exposed to exceptional precipitation, with $101.8 \mathrm{~mm}$ of rain falling, but experiment 2 traps had only received a total of $9 \mathrm{~mm}$ over the same interval. Notably, full profiles were obtained from traps exposed to the extraordinary weather in experiment 1 . Therefore, illegally-set traps discovered in wildlife crime investigations should be sampled, even if they have been subject to exceptional wet weather conditions, as there is a good chance that human DNA may have persisted. 
This is a peer-reviewed, accepted author manuscript of the following research article: Mcleish, K., Ferguson, S., Gannicliffe, C., Campbell, S., Thomson, P. I. T., \& Webster, L. M. I. (2018). Profiling in wildlife crime: recovery of human DNA deposited outside. Forensic Science International: Genetics , 35, 65-69. https://doi.org/10.1016/j.fsigen.2018.04.002

198

199

200

201

\subsection{Carcass experiments}

Full DNA profiles were obtained from the control rabbit and corvid carcasses that had been left indoors for 10 days in experiments 3 and 4 (Table 1). However, a rapid decline in recovery of DNA over time was observed from carcasses left outside.

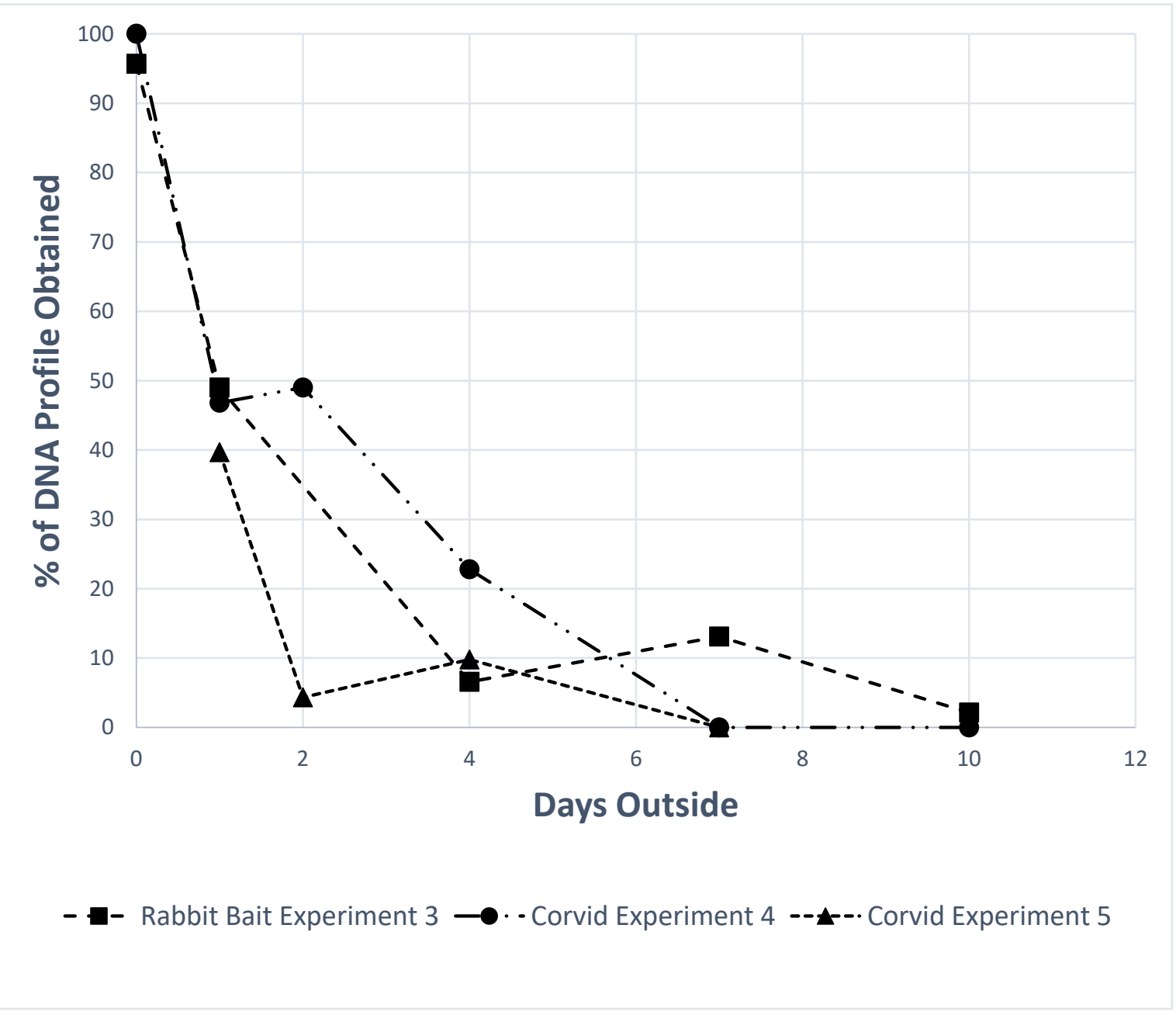

Figure 2: Average percentage of DNA profile obtained (\%) from samples collected from different carcass types left outside for different periods of time after DNA transfer in experiments 3, 4 and 5. The average percentage DNA profile is calculated from two separate trap samples on the same day at the same time. 
This is a peer-reviewed, accepted author manuscript of the following research article: Mcleish, K., Ferguson, S., Gannicliffe, C., Campbell, S., Thomson, P. I. T., \& Webster, L. M. I. (2018). Profiling in wildlife crime: recovery of human DNA deposited outside. Forensic Science International: Genetics , 35, 65-69. https://doi.org/10.1016/j.fsigen.2018.04.002

210 The results of the rabbit bait experiment show a clear drop in percentage of DNA profile obtained over time (Figure 2), and the treatment effect is significant $(F(5,5)=69.94, p<0.01)$. The percentage of DNA profiles obtained at time 0 were $100 \%$ and $91.3 \%$ dropping to $45.7 \%$ and $52.2 \%$ after 1 day outside. From 4 days, all profiles were less than $20 \%$ complete, dropping to less than $5 \%$ complete at 10 days.

A major issue with sampling the rabbit baits was how quickly the carcasses decomposed. Seven days after handling, the rabbit carcasses had severely decomposed making sampling very difficult. Consequently, for the last two samples DNA collection was undertaken at the scene. The lack of DNA recovered from either of the 10 days samples suggests that DNA is unlikely to be recovered from severely decomposed remains (Figure 2). DNA persistence drops dramatically between the day 1 and day 4 samples, with no reportable profiles obtained at 4 days. We are unable to comment on the persistence of DNA up to 3 days as no samples were taken at points between this range. For casework, provided the carcass appears reasonably fresh, DNA profiling could be successful.

The corvid experiments, showed a similar decline in the quality of STR profiles over time (Figure 2). The effect of treatment was significant for experiment 4 $(F(6,7)=57.10, p<0.01)$ but not for experiment $5(F(3,4)=586.3, p=0.66)$, although this could be due to a lack of controls for this experiment (Table 1).The highest quality profiles were recovered from the immediate samples (experiment 4 only, Figure 2). This was followed by a significant decrease in percentage of DNA profile obtained after 1-2 days in the outdoor environment (Figure 2). No DNA profiles were recovered from treatments involving 7 or 10 days outside. There are numerous factors that could have affected the quantity of DNA transferred and the quality and quantity of the DNA collected between duplicates and after different time periods. The corvid carcasses were relatively decomposed after 7 days and at 10 days a number of feathers had fallen away. This meant that a large proportion of the DNA transfer area had been lost. The actions of flies and other invertebrate scavengers may reduce the amount of DNA on the surface. In general, higher quality profiles were recovered from corvids in experiment 4 than experiment 5 . One major variable 
This is a peer-reviewed, accepted author manuscript of the following research article: Mcleish, K., Ferguson, S., Gannicliffe, C., Campbell, S., Thomson, P. I. T., \& Webster, L. M. I. (2018). Profiling in wildlife crime: recovery of human DNA deposited outside. Forensic Science International: Genetics , 35, 65-69. https://doi.org/10.1016/j.fsigen.2018.04.002

between the two corvid experiments was precipitation. The day 7 samples from experiment 4 had only been exposed to $8.4 \mathrm{~mm}$ of rain, whereas the day 7 samples from experiment 5 were exposed to $46.8 \mathrm{~mm}$. This difference in precipitation between the two experiments could account for the lower quantities and poorer profiles in the second experiment. Although this variation in rainfall is typical in Scotland, DNA transferred onto substrates in dryer cooler conditions may persist for much longer periods of time. Results from both experiments show that even after rain (S3), reportable DNA samples can be recovered from corvid carcasses after a 2 day period.

\subsection{Bird of prey experiment}

A further, small experiment was carried out on 4 bird of prey carcasses left outside for 1 day. The highest quality profile was recovered from the buzzard with $78.3 \%$ profile obtained, followed by the sparrowhawk (67.4\%), and both of these profiles were considered to be reportable (i.e. $>50 \%$ complete). The profile results recovered from the tawny owl $(0 \%)$ or kestrel $(17.4 \%)$ were not reportable.

The lack of DNA recovered from the owl may be due to unique feather structures found in this order of birds [19]. Furthermore, the owl was much wetter than the other birds during DNA collection and this may have impaired DNA recovery. The kestrel had a much lower quality profile than the other raptors, which may be due to the loss of feathers on its back. Overall, this small experiment has demonstrated that human touch DNA can be recovered from bird of prey carcasses after 1 day outside. It had rained during the experiment $(0.8 \mathrm{~mm}$ precipitation), so bird of prey carcasses discovered in wildlife crime investigation should be sampled, even if they have been subject to wet weather conditions. As no carcasses were left for longer, it cannot be demonstrated whether DNA would persist for longer than 1 day on raptor carcasses. However, the results from the corvid experiment illustrate where recovery of human DNA may be possible; as with the rabbit carcasses, provided no significant decomposition is observed, human DNA recovery should be attempted from bird carcasses in criminal casework. 
This is a peer-reviewed, accepted author manuscript of the following research article: Mcleish, K., Ferguson, S., Gannicliffe, C., Campbell, S., Thomson, P. I. T., \& Webster, L. M. I. (2018). Profiling in wildlife crime: recovery of human DNA deposited outside. Forensic Science International: Genetics , 35, 65-69. https://doi.org/10.1016/j.fsigen.2018.04.002

271

272

\subsection{Comparison of all substrates.}

When comparing the results of all substrate types a clear difference is seen between the results from the traps and all carcasses. Figure 1 highlights that the average percentage of DNA profile obtained in both trap experiments did not drop over time, as might be expected, but instead remained fairly consistent over the 10 day period. Contrastingly, the carcass experiments showed a rapid decline in DNA profile recovery over time, with only one reportable profile recovered at 2 days outside and no profiles recovered after this time.

There are a number of possible reasons why more touch DNA was recovered from traps than the bird and bait carcasses. Firstly, the initial amount of DNA transferred to the trap may have been higher than the DNA transferred to the carcasses. This was indeed found to be the case in the proof of concept experiment after immediate sampling (S2). The carcasses were only gripped tight enough to allow for holding but the traps needed sufficient force to set the device. In addition, the decomposition process on the carcasses meant that some of the sampling areas were compromised, but in the trap experiment no sampling areas were lost. Another significant difference between the sampling of traps and bait/corvid carcasses was the condition of the samples during DNA collection. All trap samples were dry during the minitaping procedure but some of the carcasses were damp or very wet. Interestingly, trap experiment 1 received the worst weather conditions and still produced higher quality profiles than all carcass samples. It must also be noted that evidence such as bird of prey carcasses are often disposed of in sheltered areas, such as in stone walls or rabbit burrows. Any protection from the elements may increase the chance of recovering DNA from carcasses.

\section{Conclusion.}

These experiments have demonstrated that reportable human DNA profiles can be recovered from traps, baits and birds that have been left exposed outside, even after exceptional rainfall. The time of exposure where reportable profiles can be recovered is variable, being at least 10 days for traps and at least 1 day for carcasses. For criminal casework, it is unlikely that the time interval between a crime and the 
This is a peer-reviewed, accepted author manuscript of the following research article: Mcleish, K., Ferguson, S., Gannicliffe, C., Campbell, S., Thomson, P. I. T., \& Webster, L. M. I. (2018). Profiling in wildlife crime: recovery of human DNA deposited outside. Forensic Science International: Genetics , 35, 65-69. https://doi.org/10.1016/j.fsigen.2018.04.002

301

302

303

304

305

306

307

308

309

310

311

312

location of evidence will be known. Our results suggest that recovery of DNA from illegally-set traps should always be attempted, and recovery from carcasses should be attempted providing only limited decomposition is observed, irrespective of rainfall levels.

The recovery of human touch DNA from evidence retrieved from outdoor locations during bird of prey crime investigations, or indeed in other crimes, may provide a key identification tool for linking or excluding suspects. The recovery of human DNA from traps, bird of prey carcasses and bait carcasses should be applied as soon as possible to assist with raptor persecution investigations.

\section{Acknowledgements}

We would like to thank the SPA Forensic Services in Dundee who carried out all of the DNA profiling for this project. Dr Gill Hartley and Sherryn Ciavaglia for advice and support during the project and David Kenyon, George Campbell and John Simpson for providing the carcasses used in the study.

\section{Funding}

This research did not receive any specific grant from funding agencies in the public, commercial, or not-for-profit sectors.

\section{References}

[1] M. Taylor, RSPB British birds of prey, Bloomsbury Publishing PIc, London, 2010.

[2] The Royal Society for the Protection of Birds (RSPB). The illegal killing of bird of prey in Scotland: 1994-2014: a review. https://www.rspb.org.uk/Images/illegalkilling_tcm9-411686.pdf (accessed July 2017).

[3] Scottish National Heritage. Wildlife \& Countryside Act 1981, [online]. http://www.snh.gov.uk/protecting-scotlands-nature/protected-species/legalframework/wca-1981/ (accessed July 2017) 
This is a peer-reviewed, accepted author manuscript of the following research article: Mcleish, K., Ferguson, S., Gannicliffe, C., Campbell, S., Thomson, P. I. T., \& Webster, L. M. I. (2018). Profiling in wildlife crime: recovery of human DNA deposited outside. Forensic Science International: Genetics , 35, 65-69. https://doi.org/10.1016/j.fsigen.2018.04.002

[4] The Scottish Government. Wildlife crime in Scotland - 2015 annual report ISBN: 978-1-78652-619-9. Published by The Scottish Government; 2016.

[5] D.P. Whitfield, \& A. H. Fielding. Analyses of the fates of satellite tracked golden eagles in Scotland. 2017 .Scottish Natural Heritage Commissioned Report No. 982.

[6] R.A.H. Van Oorschot, K.N. Ballantyne, R.J. Mitchell, Forensic trace DNA: a review, Investigative Genetics 1 (14) (2010) 1-17.

[7] R.A. Wickenheiser, Trace DNA: a review, discussion of theory, and application of the transfer of trace quantities of DNA through skin contact, Journal of Forensic Science 47 (3) (2002) 442-450.

[8] S.F. Petricevic, J. Bright, S.L. Cockerton, DNA profiling of trace DNA recovered from bedding. Forensic Science International 159 (2006) 21-26.

[9] G.N. Rutty, An investigation into the transference and survivability of human DNA following simulated manual strangulation with consideration of the problem of third party contamination, International Journal of Legal Medicine 116 (3) (2002) 170-173.

[10] S. Mawlood, L. Dennany, N. Watson, B. Pickard, Analysis of DNA from fired cartridge casings, International Journal of Biological, Biomolecular, Agricultural, Food and Biotechnological Engineering 9 (8) (2015) 840-846.

[11] R.A.H Van Oorschot, M. Jones, DNA fingerprints from fingerprints, Nature 387 (6635) (1997) 767.

[12] J.J. Raymond, S.J. Walsh, R.A. Van Oorschot, P. Gunn, C. Roux, Trace DNA: an underutilized resource or Pandora's Box? A review of the use of trace DNA analysis in the investigation of volume crime, Journal of Forensic Identification 54 (6) (2004) 668-686.

[13] D.J. Daly, C. Murphy, S.D. McDermott, The transfer of touch DNA from hands to glass, fabric and wood, Forensic Science International: Genetics 6 (2012) 41-6.

[14] S.S. Tobe, J. Govan, L.A. Welch, Recovery of human DNA profiles from poached deer remains: A feasibility study, Science and Justice 51 (2011) 190-195. 

wildlife crime: recovery of human DNA deposited outside. Forensic Science International: Genetics , 35, 65-69. https://doi.org/10.1016/j.fsigen.2018.04.002

[15] S.S. Tobe, S. Bailey, J. Govan, L.A. Welch, Recovery of human DNA profiles from poached deer remains part 2: Improved recovery protocol without the need for LCN analysis, Science and Justice 53 (2013) 23-27.

[16] H. Dong, J. Wang, T. Zhang, J. Ge, Y. Dong, Q. Sun, C. Liu, C. Li, Comparison of preprocessing methods and storage times for touch DNA samples, Croatian Medical Journal 58 (2017) 4-13.

[17] J.J. Raymond, R.A.H. Van Oorschot, P.R. Gunn, S.J. Walsh, C. Roux, Trace evidence characteristics of DNA: a preliminary investigation of the persistence of DNA at crime scenes. Forensic Science International: Genetics 4 (2009) 26-33.

[18] A. Lowe, C. Murray, J. Whitaker, G. Tully, P. Gill, The propensity of individuals to deposit DNA and secondary transfer of low level DNA from individuals to inert surfaces, Forensic Science International 129 (1) (2002) 25-34.

[19] G.M. Lilley, A study of the silent flight of the owl, American Institute of Aeronautics and Astronautics (1998) 1-6.

\section{Ref A}

S. M. Redpath, A. Amar, A. A. Smith, D. B. A. Thompson \& S. Thirgood, People and nature in conflict: can we reconcile hen harrier conservation and game management? Species Management: Challenges and Solution for the 21st Century. (Eds J. Baxter \& C. A. Galbraith). The Stationary Office, Edinburgh 2010.

\section{Ref B}

D. Parrott, Impacts and management of common buzzards Buteo buteo at pheasant Phasianus colchicus release pens in the UK: a review European Journal of Wildlife Research 61 (2), (2015) 181-197.

Ref C

UK Raptor Working Group, Report of the UK Raptor Working Group. Joint Nature Conservation Committee, Peterborough, UK 2000. 